\title{
Nuevos estándares del ejercicio de la función pública de planificación
} territorial urbana. Análisis del Artículo 28 decies de la Ley General de Urbanismo y Construcciones

\section{New Standards for the Exercise of the Public Function of Urban Territorial Planning. Analysis of Article 28 decies of the General Law of Urbanism and Constructions.}

\author{
Paola Román Fuentealba ${ }^{1}$
}

\begin{abstract}
RESUMEN
La planificación territorial urbana y sus instrumentos han experimentado variadas reformas, de manera reciente. El aumento de la participación ciudadana, la incorporación de la imagen objetivo y la inclusión de estándares mínimos en la creación de estos instrumentos son solo algunas de las modificaciones introducidas por la legislación, para efectos de contribuir en la trasparencia del mercado del suelo. En dicho contexto, este artículo se centra en el análisis del artículo 28 decies de la Ley General del Urbanismo y Construcciones, el cual es la piedra angular de la nueva forma de planificar territorialmente en Chile. El presente trabajo aborda en forma pormenorizada cada nuevo estándar, apoyándose en la reciente legislación y en la actual Política Nacional de Desarrollo Urbano.
\end{abstract}

Palabras clave: motivación, cohesión territorial, instrumentos de planificación territorial

\begin{abstract}
Urban territorial planning and its instruments have undergone several reforms recently. The increase in citizen participation, the incorporation of the objective image and the inclusion of minimum standards in the creation of these instruments, are just some of the modifications introduced by the legislation in order to contribute to the transparency of the land market. In this context, this article focuses on the analysis of Article 28 decies of the General Law of Urban Planning and Construction, which is the cornerstone of the new way of planning territorially in Chile. This paper deals in detail with each new standard, based on recent legislation and the current National Urban Development Policy.
\end{abstract}

Keywords: motivation, territorial cohesion, territorial planning instruments

Abogada, Universidad de Chile. Magíster en Derecho Público Universidad de Valparaíso. Profesora de Derecho Administrativo en la Universidad de Las Américas. Correo electrónico: roman.fuentealba@gmail.com 


\section{Introducción}

Nuestro país arrastra problemas importantes en materia de planificación territorial desde hace muchas décadas. Lo anterior no es solo producto de la irregular forma en que nació su normativa, sino también de los lentos avances que ha tenido la reglamentación especifica del área, en los últimos cincuenta años.

El Derecho Urbanístico nacional, sin embargo, se encuentra hoy en un proceso de fortalecimiento y de transformación. Lo anterior, por un lado, debido a la presencia de la Política Nacional de Desarrollo Urbano (en adelante PNDU), que aporta directrices que obligan a concebir la planificación territorial con parámetros que no se encontraban presentes antes del año 2014. Y, por otro lado, se debe a la presencia de la Política Nacional de Ordenamiento Territorial (en adelante PNOT), pues ambas, en forma complementaria, descansan sobre principios jurídicos propios del Derecho Urbanístico, que serán objeto de revisión en este artículo. Cabe hacer presente que PNOT tiene el rol de orientar la PNDU y otras políticas públicas en que se enmarcan determinaciones estratégicas con efectos nacionales, conteniendo un glosario muy completo de términos de recurrente frecuencia en materias de ordenamiento territorial.

A lo anterior se suma el bloque de legalidad compuesto por la Ley $\mathrm{N}^{\circ} 21.078$ sobre Transparencia del Mercado del suelo e Impuesto al aumento de valor por ampliación del límite urbano y por la Ley $\mathrm{N}^{\circ}$ 21.074 sobre Fortalecimiento de la Regionalización del país, que marcaron el inicio de una nueva forma de planificar territorialmente en Chile, a partir de agosto de 2018. Tanto las políticas públicas mencionadas como los dos cuerpos legales referidos propician las bases fundamentales para el ejercicio de la potestad pública planificadora.

Este artículo busca analizar los estándares mínimos exigidos por el legislador, al tiempo que la Administración, en su conjunto, ejerza la función pública de planificación territorial. Esta es una actividad a través de la cual se definen ciertas directrices de actuación pública, para la consecución de determinados fines públicos. En el caso especial de la planificación territorial, se enfatiza que es un proceso formalizado, mediante el cual se determinan las propuestas de desarrollo de un territorio, estableciendo objetivos de corto, mediano y largo plazo, acorde al interés general. Lo anterior, cuidando y distribuyendo el uso del suelo de la forma que contempla el Artículo 28 decies en sus estándares, los cuales deberán quedar plasmados en cada Instrumento de Planificación Territorial (en adelante IPT o IPTs).

Estos IPTs no se vinculan entre sí en un plano de igualdad, sino que, por el contrario, obedecen a un orden jerárquico. Dicho orden está asociado con la jerarquía orgánica que presenta la Administración del Estado. Esto explica por qué Cordero Quinzacara (2007) alude a la llamada cláusula de prevalencia, que opera en favor de los instrumentos que tienen mayor nivel jerárquico, lo que desplaza el poder de decisión desde las entidades locales al poder central. Sin embargo, más allá de la jerarquía, todos IPTs quedan sometidos a la LGUC y a su ordenanza, ya que estas normas priman por sobre las disposiciones contempladas en ellos.

\section{Análisis del Artículo 28 decies de la Ley General de Urbanismo y Construcciones}

Antes de proceder a analizar el Artículo 28 decies, debemos señalar que la planificación urbana es una especie de planificación territorial que tiene por objeto encausar un proceso de control sobre el desarrollo de las ciudades, con el fin de ordenarlas espacialmente, ofrecer oportunidades de inversión por medio de proyectos, cuidar sus recursos, proteger el bien común y hacer la vida de las personas más llevadera, plena 
y segura. Esto proporciona una mirada acotada a la planificación territorial urbana en específico, cuyos niveles de aplicación son: planificación a nivel nacional, regional, intercomunal y comunal.

Es importante señalar que en Chile no existe un único IPT, sino que hay múltiples instrumentos que cumplen tal objetivo. Cordero Quinzacara (2007) advierte que estos instrumentos "comprenden objetivos globales que [permiten] el desarrollo integral y armónico del sistema de asentamientos humanos", y agrega que "cada uno tiene un ámbito diverso de extensión territorial" (pp. 277-284). Lo anterior es efectivo, ya que, en la actualidad, y de conformidad con el Artículo 1.1.2 de la Ordenanza General de Urbanismo Construcción (en adelante OGUC), los IPTs con que cuenta Chile son los siguientes: a) Plan Regional de Desarrollo Urbano, b) Plan Regulador Intercomunal o Metropolitano, c) Plan Regulador Comunal, d) Plan Seccional y e) Límite Urbano y los planes de detalle.

Cada uno de estos instrumentos tendrá un ámbito de acción propio y definido, tanto en relación con la superficie del territorio que abarcan como con las materias y disposiciones que contienen. En tal entendido, todos los IPTs seńalados deben cumplir los estándares que ha proporcionado el legislador, pues planificar territorialmente es una función pública que persigue el interés general. En lo que sigue se realiza un estudio de cada uno de ellos, según los literales del mencionado artículo.

\subsection{Primer estándar: la expresión de las motivaciones y objetivos específicos perseguidos en cada caso, especialmente cuando se realicen cambios en las propuestas, anteproyectos o proyectos}

\subsubsection{Expresión de las motivaciones}

De la Constitución Política de la República puede desprenderse la idea que toda actuación estatal debe ser fundada. Esto, de conformidad con el Artículo 8, el cual dispone que los fundamentos y procedimientos de los actos del Estado deben ser públicos y, además, de la exigencia del Artículo $19 \mathrm{~N}^{\circ} 2$ de la Carta Fundamental. Este declara que ni la ley ni autoridad alguna podrán establecer diferencias arbitrarias, lo cual obligaría a los funcionarios a dar razón de sus decisiones. Además, la Ley $\mathrm{N}^{\circ} 19.880$ sobre Procedimientos Administrativos es más explícita aún, cuando exige expresamente esta fundamentación en sus artículos 11 y 41 .

La exigencia de motivar el acto administrativo materializa uno de los pilares fundamentales de un Estado Constitucional de Derecho, que es la rendición de cuentas por parte de la Administración del Estado. En efecto, la fundamentación de las decisiones administrativas permite a las autoridades judiciales o administrativas realizar un adecuado control sobre el razonamiento jurídico, fáctico y técnico de la administración. Esto garantiza eliminar la eventual sensación de discrecionalidad arbitraria, desviación de poder o, derechamente, corrupción en el acto en cuestión ${ }^{2 .}$

Para autores como Maqueda (2010), la motivación se enmarca en las dinámicas de una decisión normativa racional, ya que primero interviene la inteligencia, eligiendo razonablemente los medios y ordenándolos al fin querido, y después los quiere la voluntad. La ley se conforma por la actuación conjunta de la inteligencia y la voluntad del Estado, expresada a través de sus agentes. El autor no solo expresa aquello;

\footnotetext{
En concepto de Pérez Ramírez (2016), existe una vinculación directa entre la escasa motivación de las decisiones y la corrupción. Esta encuentra su terreno mejor abonado cuando las decisiones públicas se toman en régimen de práctico monopolio (personal u organizacional), con amplias facultades discrecionales, sin criterios acotados de decisión y sin mecanismos que obliguen a la rendición de cuentas. Por el contrario, cuando el agente decisor es plural o el poder es consensuado, los criterios de decisión objetivos son tasados y la fiscalización y rendición de cuentas es muy estricta, la corrupción se halla en un medio ambiente mucho más hostil.
} 
además proporciona señales importantes para delimitar tanto el continente como el contenido de la decisión. Así, esta debe manifestarse (de cualquier forma) y ser razonable, motivada, con una base sólida, justa, con un objetivo bien definido y conocida por todos aquellos a quienes afecte. Se sigue de lo anterior que dicha decisión debe ser adoptada por aquel que tenga competencia para aquello (pp. 473-479).

Cumplir con lo anterior significa propiciar un alto estándar en la motivación del acto o decisión administrativa, más aún si esta recae sobre cuestiones técnicas, las cuales son esenciales en planificación territorial. La decisión de la autoridad planificadora nunca podría sustentarse en apreciaciones subjetivas, vagas, confusas, imprecisas y sin la adecuada referencia a los estudios técnicos que la sustentan, sea esta la decisión definitiva o aquella que se invoque en el caso de cambios como prevé el legislador de 2018.

\subsubsection{Señalar objetivos generales y específicos perseguidos en cada caso}

En general, un objetivo es aquello a lo que se tiende con pretensiones de conseguirlo. Por tanto, esta tarea consiste en la expresión formal de la voluntad, de resolver los problemas actuales, prevenir los futuros, aprovechar las oportunidades y satisfacer las demandas de la población, así como de cumplir las directrices de rango superior, si existen, y las previsiones de niveles institucionales de rango inferior al del ámbito del estudio (Gómez, 2008).

Como en cualquier estudio que pretenda una intervención territorial, además de ser fundado se deben expresar los objetivos generales y específicos que pretende alcanzar con la mencionada acción. Lo anterior es una cuestión que solo compete determinar a la autoridad administrativa bajo la metodología que esta elija.

Gómez (2008) identifica objetivos generales como equilibrio territorial, integración, funcionalidad, conservación de procesos ecológicos esenciales, respeto por procesos ecológicos para la sostenibilidad, calidad de vida, entre otros. En mi opinión, cada uno de estos objetivos generales puede subsumirse en cualquier otro objetivo que cuente con mayor especificidad.

\subsection{Segundo estándar: Considerar información suficiente sobre la realidad existente y su evolución previsible}

\subsubsection{Obtención de información suficiente}

Otro elemento de suma importancia que ha introducido la nueva ley es considerar, al tiempo de la planificación, toda la información suficiente sobre la intervención territorial a realizar. Dicha información debe abarcar el mayor conocimiento de los elementos fácticos, jurídicos y técnicos de la zona que se pretende intervenir. En mi concepto, hay información suficiente solo cuando aquella es rica en precisión, pertinencia, claridad, actualidad y completitud. Estas cualidades son las que permiten adoptar la mejor y más fundada decisión administrativa y, con ello, optimizar el ejercicio del control de motivos al que me referí en el numeral anterior.

En el mismo orden de ideas, y si recurrimos a la literatura especializada en la materia, los expertos han puesto énfasis en el método para recabar la información que se debe tener en consideración al tiempo de la planificación. Así, toda ordenación territorial se realiza a través de un conjunto de fases que comienzan con el necesario conocimiento del territorio en estudio. Lo anterior plantea la siguiente interrogante: ¿cuánta información debe manejar el planificador? En concepto de Fernández y Muguruza (2015), la respuesta es compleja. Señalan estos teóricos que "en principio parece necesario contar con toda la información posible, la cual permita comprender la dinámica y estructura del sistema territorial, es la situación óptima, sin embargo, hay limitaciones económicas, temporales y técnicas” (p.12). 
Reconocer estas limitaciones es básico para operar de la forma más eficiente y eficaz posible, siendo conscientes de que las restricciones de tiempo y dinero afectarán al adecuado desarrollo de la planificación. Aun cuando aquellas dificultades se presenten, siempre se debe cumplir con una suerte de metodología o protocolo que se expresa por fases que a continuación se desarrollan. En la primera se obtiene la información y se establece un primer análisis y cribado de esta. La segunda fase es de diagnóstico, que sirve para conocer el estado del territorio. Tanto el análisis como el diagnóstico, en algunas oportunidades, suelen mezclarse y se unen en una sola fase llamada "Análisis y Diagnóstico", teniendo siempre en consideración que el análisis es previo al diagnóstico. Este último será cada vez más preciso, cuanta mayor y cierta sea la información que arroje el análisis (Fernández y Muguruza , 2015, p. 7).

Agotadas las fases anteriores se entra a la etapa nuclear de la ordenación territorial, esto es, la planificación. En ella, a partir de los objetivos y fines establecidos en las fases anteriores, se procede a la oportuna distribución de actividades en el territorio y se propone, además, la distribución teórica de los usos de suelo. Finalmente se realiza una suerte de cotejo fáctico entre los objetivos perseguidos en materia territorial, previamente delimitados, y el cumplimiento de los mismos.

Una exitosa, correcta y completa planificación debe recoger, por lo tanto, variados elementos de juicio o información, sea esta fáctica, jurídica o técnica. Dentro de todos los elementos en esta última información se pueden mencionar, al menos, los estudios relativos al medio físico, el cual obedece a la realidad natural o física (biótica y abiótica) del espacio; los estudios geológicos y geomorfológicos, meteorológicos y climáticos, hidrológicos, estudios sobre fauna y vegetación, estudios edáficos (el suelo como soporte de la vegetación), estudios del paisaje (por poblamiento y por recursos culturales), estudios demográficos y estudios de actividades económicas, entre otros (Fernández y Muguruza , 2015, p. 17-25).

Finalmente, a partir de la información adecuada, será posible lograr IPTs oportunos, realistas, coherentes con el entorno, holísticos, con un enfoque sistémico, participativos, incentivadores y dinámicos, integradores y capaces de incluir la variedad y diversidad de actividades y morfología de un territorio, en suma, herramientas eficientes y eficaces (Betsalel, 2001, pp. 72-74).

\subsubsection{Planificar el futuro territorial y enfrentar la incertidumbre}

El legislador ha realizado un interesante alcance en la Ley $\mathrm{N}^{\circ} 21.078$. No solo ha positivado la obligación de considerar la información suficiente sobre la realidad existente, sino que, además, ha añadido un elemento clave para el desarrollo de las ciudades en general: incorporar al proceso de planificación el factor del futuro o "la evolución previsible".

Planear el futuro de una ciudad se convierte, a través de esta norma, en un desafío que impone a la Administración una suerte de exigencia pública de no solo cubrir el escenario que tangiblemente es capaz de percibir en el presente, sino además de prepararse para dimensionar el futuro, a partir de la información con la que cuenta hoy. En literatura especializada en Derecho Urbanístico, la llamada "evolución previsible" suele conocerse como "la incertidumbre" o como la "red de incertidumbre"3.

El concepto mencionado ha sido acuñado por Rafael Crisosto (2017), quien a través de un estudio de caso expone que la planificación urbana de un megaproyecto urbano fracasa en términos de su planificación, debido a la no consideración de una multiplicidad de factores que forman la "red de incertidumbre", que llega a manifestarse e imponerse sobre aquello que parecía rígidamente constituido. Especial énfasis propone este autor en relación con que cuestiones incluso de filiación política impactan en una buena planificación, como lo es desvincular por aquellos motivos a quien sea el líder técnico del proyecto. 
En dicho contexto, Fernández Güell (2015) destaca que "cualquier planificador urbano debe, indefectiblemente, ser capaz de interpretar los tres grandes rasgos propios de las ciudades contemporáneas. Se trata de la complejidad, diversidad e incertidumbre, que acompañan a la mayoría de los fenómenos urbanos" (p. 18). El autor identifica la incertidumbre o el futuro como una dificultad en el ejercicio de la planificación, sin embargo, advierte que dicho problema no debe socavar la aspiración de lograr un mejor futuro para cada ciudad, sea este a quince o veinte años plazos.

Para lograr el mejor manejo de los desafíos que significa programar el futuro, existen métodos que se pueden utilizar para describir dicha aproximación, entre los cuales están: prognosis, previsión, predicción, proyección y prospectiva. Todos estos métodos están dados para reducir la incertidumbre a un nivel de duda "razonable" que no implique desconocimiento de los resultados o impactos más relevantes de las acciones a acometer (Salas Bourgoin, 2013, p. 28).

De la variedad de métodos indicados, el planificador deberá inclinarse por aquel que le proporcione las mejores herramientas para enfrentar el carácter multidimensional de las decisiones que debe adoptar al minuto de planificar el futuro. El método que elija la Administración debe ser aquel que le proporcione proximidad con el cumplimiento más ajustado a la función pública de planificar, esto es, proceder en forma eficiente y eficaz, propiciando responder al interés general de la sociedad y reducir los niveles de incerteza al mínimo.

En ese contexto, tanto para Fernández Güell y Salas Bourgoin como para la CEPAL, el método prospectivo aparece como "un proceso de anticipación, de exploración de la opinión experta de la comunidad y de la sociedad civil, procedente de redes de personas, instituciones, gobiernos, empresas y la sociedad civil, que en forma estructurada, interactiva, participativa, coordinada y sinérgica crean visiones de futuro (Georghiou y otros, 2008)" (CEPAL, 2016, p. 197). Ante tales características, existe consenso literario de que este método es el más recomendable para los países de Latinoamérica.

\subsection{Tercer estándar: Ajustarse a los principios de sustentabilidad, cohesión territorial y eficiencia energética, procurando que el suelo se ocupe de manera eficiente y combine los usos en un contexto urbano seguro, saludable, accesible universalmente e integrado socialmente}

\subsubsection{Planificación territorial en base a principios jurídicos del Derecho Urbanístico}

Cuando hablamos de planificación territorial, a modo genérico, nos referimos a "intervenciones puntuales, temáticas, territoriales y temporales, en el espacio geográfico que se pretende intervenir" (Salas y Budde, 2008 , p. 14). Frente a aquello, el legislador configuró ciertos principios jurídicos especiales que pertenecen al Derecho Urbanístico como disciplina independiente de otras ramas del Derecho. Estos principios no son Principios Generales del Derecho (Vergara, 2012, p. 67); son directrices jurídicas especiales que deben estar presentes al tiempo de planificar y que orientan el ordenamiento territorial y el proceso de planificación propiamente tal.

Los que se tratan en este literal provienen, en su mayoría, de la influencia que ha tenido el Derecho Urbanístico español en Latinoamérica (Carrasco, 2008, p. 85). En efecto, Cordero Quinzacara (2011) ha señalado que "la ordenación del territorio responde a una tradición europea que aspira a plasmar espacialmente las políticas económicas, sociales, culturales y ecológicas. A su vez, sus objetivos están centrados en tres puntos: desarrollo económico y equilibrado de las regiones, mejoramiento de la calidad de vida de las personas y la protección del medio ambiente. Todo esto se engloba bajo la idea 
de una utilización racional del territorio, lo cual exige una planificación como instrumento necesario y esencial" (p. 213).

\subsubsection{Sobre la cohesión territorial}

En este punto desarrollaré, con mayor énfasis, el concepto de cohesión territorial, ya que el principio de sustentabilidad se encuentra más profundizado y mejor tratado por la disciplina del Derecho Ambiental. En el caso del principio de eficiencia energética, se analizará en el apartado 2.5.2.

Para abordar un concepto de cohesión territorial recurriré a legislación y literatura española que, por cierto, manejan estos conceptos ya desde un tiempo considerable. Para efectos normativos, el Artículo 3 del Real Decreto Legislativo 7/2015, del 30 de octubre, por el que se aprueba el texto refundido de la Ley de Suelo y Rehabilitación Urbana española, dispone en su numeral tercero la sujeción a los Principios de desarrollo territorial y urbano sostenible. Según este: "Los poderes públicos formularán y desarrollarán, en el medio urbano, las políticas de su respectiva competencia, de acuerdo con los principios de competitividad y sostenibilidad económica, social y medioambiental, cohesión territorial, eficiencia energética y complejidad funcional, procurando que, esté suficientemente dotado, y que el suelo se ocupe de manera eficiente, combinando los usos de forma funcional” (2015, p. 8).

La cohesión territorial podría definirse como un principio para las actuaciones públicas encaminadas al logro de objetivos, como crear lazos de unión entre los miembros de una comunidad territorial (cohesión social) y favorecer su acceso equitativo a servicios y equipamientos (equidad/justicia espacial). De igual modo, busca configurar un auténtico proyecto territorial común (identidad), partiendo del respeto a la diversidad y a las particularidades, articular y comunicar las distintas partes del territorio y romper las actuales tendencias hacia la polarización y desigualdad entre territorios (de la Unión Europea o de España). Lo anterior, aprovechando las fortalezas y rasgos inherentes de cada uno de ellos. Se trata, además, de buscar la cohesión o coherencia interna del territorio, así como la mejor conectividad de dicho territorio con otros vecinos (Fernández et al, 2009, pp. 159-160).

Interesante es la asociación que efectúan López y Faginas (2019) entre la cohesión territorial y el espacio público, al cual consideran como el lugar donde se une la ciudad con sus ciudadanos, por lo que adquiere un carácter particular como elemento estructurante de la vida y del sistema urbano. Las autoras citadas sostienen que la cohesión territorial se enmarca en la construcción de un proyecto para la integración del territorio y constituye una elaboración prospectiva en la que se incluye el espacio público de la ciudad como elemento clave. En síntesis, el objetivo central de la cohesión territorial es lograr la conexión espacial y la integración social en las ciudades. Por eso, los espacios públicos son elementos estratégicos para la construcción de territorios de inclusión socioespacial y es aquí, como señalan las autoras, donde la gestión integral urbana tiene una gran responsabilidad y un desafío (p. 134).

Ahora bien, ¿es posible mejorar si el sistema territorial se daña por actos de exclusión, de segregación o de inequidad territorial? La respuesta es sí; siempre son posibles y necesarias nuevas formas de cohesión territorial. Allí donde aparezcan desequilibrios o desigualdades territoriales sustantivas deben ser abordadas por la política de cohesión territorial del país que lo sufra. Algunos ejemplos son: tipos de áreas urbanas que entran en declive social, regiones rurales con procesos agudos de despoblación, ámbitos con inmigración mayoritaria, localidades en extremo alejadas, entre muchos ejemplos de fracturas territoriales.

Este literal es uno de los más trascendentes bajo el prisma de la Política Nacional de Desarrollo Urbano, pues parte de esta política pública es la integración social en y con las localidades apartadas. Esto, mediante 
planes y programas de viviendas sociales y equipamiento adecuados a las características particulares de las distintas localidades. Además, por medio de la incorporación del aporte de las localidades apartadas en las iniciativas de inversión en conectividad y servicios de infraestructura, y el desarrollo de programas de apoyo a la organización y gobierno de las localidades menores, ejes rectores del consenso alcanzado.

Finaliza este análisis con el alcance que debe concretar la Política Nacional de Ordenamiento Territorial, ya que su aporte debiese tender, según su considerando octavo, a conducir "la acción del Estado y de los actores privados y la sociedad civil a nivel nacional hacia la configuración de un territorio armónico, integrado, seguro e inclusivo en su diversa y amplia geografía, y además, impulsar un proceso de desarrollo sustentable que integre las dimensiones sociales, económicas y ambientales, con identidad territorial" (Ministerio del Interior y Seguridad Pública, 2019, p. 3).

\subsection{Cuarto estándar: evitar la especulación y procurar la satisfacción de las necesidades de vivienda de la población}

\subsubsection{Sobre evitar la especulación}

En Chile, hasta febrero de 2018, no existía en la LGUC una referencia especial al fenómeno de la especulación. Consciente de aquella falencia, la intención del mensaje presidencial de 2015 estaba orientado a fortalecer la transparencia en un mercado ${ }^{4}$ que habitualmente es tildado de "gris" u "opaco", lo cual es suelo fértil para actos de corrupción urbanística (Capdeferro, 2015, pp. 233-248).

Lo anteriormente expuesto fue, a grandes rasgos, lo que motivó dicho proyecto, que manifestaba tres ejes fundamentales: mejorar los niveles de transparencia del mercado del suelo, perfeccionar el impuesto territorial y, en el caso puntual de los cambios de uso de suelo desde agrícola a urbano, establecer un tratamiento tributario específico para que los incrementos de valor generados en este proceso sean compartidos, en mayor medida, con la comunidad entera (Biblioteca del Congreso Nacional de Chile, 2018).

Para comprender este numeral es pertinente recurrir a la historia de la ley en comento. Fue el senador Carlos Montes quien expuso su posición frente a una realidad económica y social que imperaba en Chile, señalando: "creo que este proyecto es muy importante. Y si bien no resuelve plenamente un problema, nos permite avanzar. ¿Cuál es el problema al que me refiero? La realidad del suelo en Chile, que presenta muchas dificultades para regularlo como un bien y para asegurar que se halle en línea con el desarrollo más general de nuestro país. El suelo es un factor que permite una gran especulación, y en torno a él hay un mal sistema tributario, que es fuente de fortunas y no necesariamente está alineado con ciertos objetivos nacionales" (Biblioteca del Congreso Nacional de Chile, 2017).

El Parlamento, luego de debatir el proyecto, consideró oportuno que al momento de ejercitar la potestad planificadora se "evite" la especulación. Esto es, que se abstenga de la obtención de beneficios a partir de prácticas especulativas sobre el uso del suelo, en particular, por el cambio de uso, de rústico a urbano o de público a privado (Biblioteca del Congreso Nacional de Chile, 2018, p. 3).

Para Fernández Güell (2008) no solo la elevada complejidad de los procesos socioeconómicos, la diversidad de los agentes locales y la incertidumbre inherente a los fenómenos urbanos son las únicas dificultades en el ámbito de la planificación territorial. El autor sostiene que además la escasa transparencia y la elevada corrupción existente en la toma de numerosas decisiones urbanísticas, sea en países desarrollados o subdesarrollados, es otro componente que dificulta la planificación. 
La realidad que recoge el debate de la ley es una problemática que atraviesa no solo a Chile, sino que sucede en todos los países de Sudamérica ${ }^{5}$ incluso en Europa, más específicamente en España. De ahí la urgencia por propiciar que el ordenamiento territorial sea el instrumento administrativo que regule o corrija las desigualdades sociales que devienen por causa de la especulación en materia de los valores del suelo ${ }^{6}$.

¿Qué ha de entenderse por "evitar”? El Diccionario de la Lengua Española entiende por dicho término "apartar algún daño, peligro o molestia, impidiendo que suceda" (DLE, versión 23.3 en línea). Por lo tanto, la exigencia del legislador a la Administración es impedir que al tiempo de la planificación se especule. Por su parte, la palabra "especulación" es definida por el DLE como la "operación comercial que se practica con mercancías, valores o efectos públicos, con ánimo de obtener lucro" (versión 23.3 en línea).

Como advierten los expertos en esta materia, "cuando los terrenos pasan de un uso a otro, que es superior y/o aumentan su capacidad de edificación, suben rápidamente sus precios y se crean las condiciones propicias para prácticas especulativas orientadas a capturar esos incrementos de valor del suelo" (Cuenya y Corral, 2011, p. 29).

El negativo impacto económico que produce la especulación recae sustantivamente en aquellos que no poseen un gran patrimonio económico y que ven mermadas sus expectativas para acceder a la compra o arriendo de una vivienda. Por lo anterior, y casi desde un punto de vista valórico de la planificación, Torres (2005) estima que "para que exista una adecuada gestión urbana y no se incentive la especulación resulta entonces de suma importancia asumir el ordenamiento urbano, desde la perspectiva de la teoría general de la administración. Asumir — al menos - que el ordenamiento de territorio comporta las cuatro funciones básicas de la teoría de la administración: la planeación o planificación, la organización, la dirección y el control, bajo una mirada ética, ya que ordenar el territorio significa vincular las actividades humanas en el espacio con una cuantía de recursos determinados, por siempre escasos” (p. 62).

La "mirada ética" a la que se refiere Torres está íntimamente ligada a la idea de impedir que, en el proceso de planificación territorial, por parte de la Administración se realicen actos, ya sean jurídicos o no jurídicos, en post de la obtención del lucro, alejado de la transparencia tan perseguida en esta área de la economía. Así, la idea que subyace en este literal es evitar que producto de la especulación no se dimensione uno de los puntos más sensibles y pilar fundamental, a la hora de planificar. Esto es, vulnerar las posibilidades de acceso a la vivienda por parte de la población. Ante aquel posible escenario, la potestad administrativa de intervención de uso de suelo es, en sí misma, justificación suficiente para velar por un equilibrio técnico y económico en la planificación territorial.

Por lo anterior es que para Noguera (2011) "la ordenación urbanística de la ciudad, en tanto que configura los espacios y los edificios donde puede desarrollarse el uso de la vivienda, tiene que ver necesariamente con el mercado de la vivienda y, por tanto, con su precio. Ciertamente, para que haya un mercado satisfactorio de viviendas, y de suelo para construirlas, conviene que haya una oferta amplia de estos productos, y la ordenación urbanística debería hacerlo posible, en la medida que lo permitan las disponibilidades del lugar" (p. 150).

Ante la problemática expuesta, el siguiente paso es formular posibles soluciones que constituyan una alterativa para enfrentar el problema de la especulación, indistintamente del ángulo desde el cual se

Para conocimiento sobre los tipos de especulación que se suelen dar en torno al mercado del suelo, se sugiere ver Cuenya y Corral (2011).

6 Véase en extenso la completa descripción de los valores del suelo en Santa Cruz (2014). 
observe. En palabras del sociólogo Miguel Martínez (2005), "es necesario más y mejor Urbanismo, es decir, con más autoplanificación y autogestión colectivas de los bienes y servicios públicos municipales, empezando por el control popular del suelo y de los procesos de construcción y adjudicación de viviendas a un precio justo" (p. 142). La obra de Martínez es extensa, siendo el precursor de la relación entre el urbanismo y la sociología ${ }^{7}$. A mi juicio, sumado al mejor urbanismo que propone Martínez, otra variable importante es realizar un profundo control de motivos, tal como ya fue desarrollado en el apartado 2.1.1.

\subsubsection{Procurar la satisfacción de las necesidades de vivienda de la población}

Finalizando el estudio sobre la especulación, quisiera destacar la coherencia lógica por la que optó el legislador en este literal, ya que unió el llamado a "evitar" la especulación con procurar la satisfacción de las necesidades de vivienda de la población. Sin entrar en mayor detalle sobre cuál es la fórmula para satisfacer esa necesidad puntual, me detendré en la siguiente interrogante: ¿qué tipo de vivienda es la que satisface las necesidades de la población? A mi juicio, este punto es claro y tiene una respuesta, la cual ha sido proporcionada por la doctrina en Derecho Constitucional y en Derecho Administrativo, y es el derecho a una vivienda digna o adecuada.

En el ámbito del Derecho Constitucional, Tórtora (2012) ha sostenido que el derecho a la vivienda adecuada no se encuentra explícitamente protegido por el texto constitucional, pero es posible construirlo dogmáticamente por aplicación de una serie de normas y empleando criterios sistemáticos y finalistas de interpretación constitucional. Dicho autor realiza aquella construcción a partir de normas constitucionales de carácter general, como el artículo primero, incisos primero y cuarto de la Constitución Política de la República (en adelante: CPR), que entienden que "las personas nacen libres e iguales en dignidad y derechos" y que "el Estado está al servicio de la persona humana". Lo anterior es, para este autor, un estándar básico para la dignidad humana y la creación de un hábitat mínimo para el desarrollo personal y familiar. Asimismo, Tórtora recorre otros derechos y garantías constitucionales que se vinculan estrechamente con el derecho a la vivienda adecuada (2012, pp. 350-351).

Por parte de la Doctrina en Derecho Administrativo, Rajevic (2013) ha sostenido que, no obstante que el constituyente no contempla el derecho a una vivienda digna, hay mérito suficiente para la construcción de dicha idea, ya que distintas instancias internacionales, como la Asamblea General de Derechos Humanos, han dicho que corresponde a tener un espacio adecuado, a un costo razonable. El Comité de DD. HH. de la ONU señaló que no se trata de tener un techo sobre la cabeza, simplemente, sino un lugar donde la persona pueda desarrollarse en seguridad, en paz, en dignidad. Y dentro de los factores que se consideran para decir que una vivienda es adecuada, está el estado en que se encuentra, la asequibilidad del precio, la adecuación cultural, etc. (p. 43).

Para finalizar este punto, expondré un ejemplo de lo ocurrido el año 2011, cuando la Secretaría Regional Ministerial de Ministerio de Vivienda y Urbanismo anunció la modificación del Plan Regulador Metropolitano de Santiago 100, que promovía una ampliación del límite urbano en 10.000 hectáreas, lo que se justificaba, principalmente, en la necesidad de obtener suelo para el desarrollo de viviendas sociales. $\mathrm{Al}$ respecto, Pablo Trivelli sostuvo que "la dificultad para construir viviendas sociales en Santiago no está en la falta de suelo, sino en el precio de los terrenos. Desde fines de los 90s no se ofrecen terrenos por menos de $1 \mathrm{UF} / \mathrm{m} 2$ y los precios más bajos hoy están por sobre $1,5 \mathrm{UF} / \mathrm{m} 2$. Esto hace cada vez más difícil, si no imposible, construir viviendas sociales y la ampliación del límite urbano no hará bajar los precios

En materia de especulación, véase Martínez (2007). 
de los terrenos" (2011, p. 179). El mismo autor acota que prácticamente no hay ofertas de terrenos con precios por debajo de $1,5 \mathrm{UF} / \mathrm{m} 2$. Los conjuntos de casas de los programas de vivienda social pueden pagar hasta un máximo de $0,4 \mathrm{UF} / \mathrm{m} 2$ previo a la creación del subsidio de localización (p. 180).

Esta crítica se unió a otras provenientes de expertos, como las de Genaro Cuadros Ibánez, arquitecto urbanista y director del Laboratorio Ciudad y Territorio de la Universidad Diego Portales, quien sostuvo que "lo que busca el proyecto es hacer crecer la ciudad de Santiago, sin factibilidad de transporte público, no contando con un plan de movilidad urbana, del todo indispensable si se requiere transitar largas distancias para llegar al centro urbano de la capital (Santiago), la que en sí misma es ya una ciudad difícil de manejar y sin equipamiento necesario para poder funcionar" (Radio Concierto, 2013).

Como epílogo de lo expuesto, todos los órganos de la Administración del Estado con competencia en la creación o modelación de un IPT deben ser conscientes de que el suelo es un bien inmueble por naturaleza, finito y escaso, lo cual amerita especial consideración por el rol que desempeña desde el punto de vista económico, social y jurídico en el diario vivir de las personas. Influye en el comportamiento de estas, ya que la reacción casi natural a los problemas de acceso a vivienda se traduce en asentamientos humanos informales y así lo demuestra la literatura latinoamericana (Costa y Hernández, 2010).

$\mathrm{Al}$ concluir el análisis de este literal es preciso destacar que las materias tratadas en este apartado tienen un fuerte componente económico, por lo cual, tal como afirma Cordero Cueva, el "precio del suelo, es y será el gran desordenador urbanístico" (2016, p. 179).

\subsection{Quinto estándar: Consistencia con los estudios técnicos referidos a movilidad urbana, infraestructura sanitaria y energética, riesgos y protección del patrimonio natural y cultural}

\subsubsection{Estudios técnicos sobre movilidad urbana}

Este literal obliga, al minuto de ejercitar la potestad planificadora, a mantener la coherencia y coordinación entre los estudios técnicos del área a tratar, con las políticas sectoriales asociadas a cada materia. El requisito de actuar coordinadamente no es más que la manifestación de las exigencias a las que está sometida la Administración, en virtud del Artículo 3 inciso segundo de la Ley General de Bases de la Administración del Estado $N^{\circ} 18.575$, en la que se consagra el Principio de Coordinación, de modo explícito ${ }^{8}$.

Lo perseguido por este literal es obtener estudios técnicos completos, de modo que al momento de implementar un proceso de ordenación territorial, se incorporen factores tan relevantes como la movilidad urbana. En ese sentido, la temática del transporte aborda la dimensión técnica de los desplazamientos y apunta, principalmente, a la acción de moverse de un lugar a otro, esto es, el traslado desde un punto A hasta un punto $B$ de la ciudad. Este traslado es una actividad básica para la población, que requiere transitar y arribar a distintos destinos. Una ciudad no es un espacio agradable, seguro e inclusivo, en mi concepto, si la planificación de ella no incluye una política de traslados sostenibles en el tiempo.

No obstante lo anterior, debemos ir distinguiendo entre el concepto de transporte, el transporte sostenible y la movilidad urbana. Respecto del primer concepto, el transporte, es una actividad fundamental en la organización del territorio y se puede definir como el traslado de personas o cosas de un lugar a otro. Para que exista transporte público o privado son necesarios dos elementos: una infraestructura (que es la parte

\footnotetext{
Véase el deber de coordinación específico en materia de planificación territorial en Cordero (2007).
} 
material para transporte, como carreteras, aeropuertos, puertos, cables eléctricos, etc. y que está auxiliada por servicios como semáforos vallas, etc.) y un vehículo con conductor, que es el instrumento que permite el traslado, como el automóvil, el avión, el tren, etc. (Santa Cruz, 2014, p. 26).

El sector transporte es determinante para el desarrollo sostenible, ya que por un lado trae consigo beneficios económicos y sociales, pero, por otro, implica externalidades negativas. Los efectos negativos del transporte, como la contaminación atmosférica, el ruido y los accidentes, afectan la calidad de vida. A nivel mundial, los impactos del transporte se reflejan principalmente en el aumento del consumo de recursos y energía, así como en las emisiones relacionadas con el clima, como el dióxido de carbono (Lozano, 2018, p. 69).

Aunque no existe una definición aceptada universalmente sobre transporte sostenible, sí es pertinente tener en consideración que el transporte es sostenible cuando posee objetivos sociales, ambientales y económicos definidos. Estos deben estar en conexión con un objetivo común, esto es, ciudades más completas, urbes que integren verdaderos planes de movilidad urbana que propicien desplazamientos seguros e integrados a la ciudad.

Solo a modo de ejemplo, el Plan de Movilidad Sostenible que fue requerido en 2017 por el Gobierno Regional del Biobío, tuvo como objetivo elaborar un plan para el Área Metropolitana de Concepción (AMC), con el fin de abordar las principales problemáticas y líneas de intervención en materia de movilidad e infraestructura de transporte del AMC. Producto de los estudios técnicos realizados, sumados estos a las instancias de participación ciudadana, los resultados arrojaron que los conceptos más reiterativos fueron la mala conectividad interna en las comunas. Se argumentó la existencia de un sistema de transporte que giraba solamente en torno a la capital regional y provincial (Concepción), de modo que no se generaban alternativas para la conectividad al interior de las demás comunas. Esto generaba la existencia de sectores sin locomoción pública, potenciados por un crecimiento inmobiliario desvinculado de los temas de conectividad y un deficiente acceso a servicios, concentrados además en zonas puntuales del área metropolitana (León et al, 2019, p. 1).

Es por lo anterior que, en doctrina especializada en movilidad urbana, se considera que esta puede definirse "como la suma de desplazamientos de personas, de bienes, de informaciones y todos los efectos que estos desplazamientos producen en: (i) la organización de nuestra sociedad (modos de vida de las personas, desarrollo económico de una ciudad y otros) y (ii) en la estructuración de la ciudad (extensión y transformaciones morfológicas de las ciudades, accesibilidad a servicios y equipamientos urbanos, entre otros)" (Escudero, 2013, p. 212).

El estudio técnico, por lo tanto, debe considerar objetivos generales y específicos respecto del área a tratar, para lo cual deberá implementar la metodología pertinente para cada estudio.

\subsubsection{Estudios técnicos sobre infraestructura sanitaria y energética}

Revisaré a continuación la exigencia del legislador en materia de infraestructura sanitaria y energética. Para comenzar es fundamental establecer la necesaria coordinación entre la infraestructura y los procesos de planificación territorial. Según el DLE, se entiende por infraestructura "el conjunto de elementos, dotaciones o servicios para el buen funcionamiento de un país, de una ciudad o de una organización cualquiera" (versión 23.3 en línea). 
La infraestructura ${ }^{9}$ hace habitables los territorios al dotarlos de energía, de servicios sanitarios y accesibilidad al transporte, lo cual condiciona fuertemente el desarrollo de los asentamientos humanos y es determinante en la regulación de su capacidad de crecimiento. Esto último, al producir tanto estímulos como desincentivos económicos y sociales para la localización de la población y de la actividad económica en general.

En opinión de Humberto Eliash (2005), la relación entre espacio urbano y desarrollo económico, social y político es ineludible y lo expresa centrándose en cinco factores indispensables para lograr calidad de vida a través de un desarrollo sustentable: la participación ciudadana, la gobernabilidad de la ciudad, el espacio público, los instrumentos de planificación y la infraestructura. Una ciudad para crecer armónicamente debe lograr un equilibrio sustentable de todos los factores que inciden en su desarrollo (p. 47).

El quinto factor que recoge Eliash revela la importancia de una infraestructura adecuada para satisfacer y colmar las constantes necesidades de la población, lo cual condiciona el desarrollo económico de una ciudad y así lo han comprendido la actual PNDU y el legislador de la Ley $\mathrm{N}^{\circ} 21.078^{10}$.

En la misma línea que Eliash, Castro (2018), a propósito de la unión entre desarrollo económico y desarrollo urbano, estimó que la infraestructura y servicios de una ciudad permiten tener una idea de la calidad de vida de sus habitantes y la capacidad para desarrollarse económicamente. Es más, este autor mexicano, recogiendo las críticas a los últimos cuarenta ańos de planificación territorial en su país, y para efectos prácticos, sugiere que la planificación de la misma se ajuste a un cierto orden. Su concepto "hacer ciudad" significa contar con todo lo que demanda una ciudad para su crecimiento y desarrollo, como las necesidades de infraestructura, equipamiento y servicios urbanos. Todo esto debe de ir antes de la edificación de vivienda, aunque en el pasado ha sido al revés: primero la edificación masiva de vivienda social y después resolver las grandes demandas que requieren sus ocupantes (pp. 9-13).

Ahora bien, la justificación de participación privada en infraestructura ha sido motivada por una necesidad urgente de realizar enormes inversiones. Para mejorar el funcionamiento de la infraestructura y su cobertura, la mayoría de las empresas estatales requerirían una importante financiación adicional. Dada la escasez de fondos públicos y las necesidades de amplios sectores sociales, la mayoría de los países optaron por transferir los servicios de infraestructura al sector privado (Guash, 2005, p. 20). Este modelo ha permitido grandes avances en materia de infraestructura y servicios, pero también, en opinión de González (2006), ha debilitado las capacidades directivas del Estado para abordar materias tan importantes como la planificación y el desarrollo urbano (pp. 67-68).

Ahora bien, el legislador se ha referido en forma expresa a estudios técnicos en "infraestructura sanitaria" e "infraestructura energética", pero lo ha expresado "entre otros", lo cual deja abierta la posibilidad de abordar otro tipo de estudios en otro tipo de infraestructuras. A continuación, se detallan los requerimientos expresados por el legislador en lo relativo a infraestructura sanitaria y energética.

\footnotetext{
Para Joaquín Farinós (2007) hay dos grandes tipos de infraestructuras: las naturales (derivadas del medio físico, como un río, un valle, etc.) y las derivadas de la actuación antrópica. De entre las segundas cabe distinguir entre la infraestructura institucional y la física. Esta última se divide, a su vez, entre la social (educativa, sanitaria, centros asistenciales y culturales, edificios y equipamientos utilizados por la Administración) y la económica, también denominada infraestructura básica. Esta se compone de los servicios públicos (distribución de agua, electricidad y gas natural, recogida de basuras y depuración de residuos), los servicios de telecomunicaciones (telefonía, correo, cable, etc.), la gestión del suelo (mejora de drenajes, prevención de inundaciones y otros riesgos naturales o tecnológicos) y, finalmente, las infraestructuras de transporte (carreteras, ferrocarriles, vías fluviales, puertos y aeropuertos).

10 En la Política sobre la Infraestructura Urbana de 1985, que precede a la actual PNDU, se especificaba lo que comprendía la macro y la micro infraestructura en lo sanitario y lo energético (Ministerio de Vivienda y Urbanismo y Programa de las Naciones Unidas para el Desarrollo, 2014).
} 
En materia sanitaria ${ }^{11}$, como señala Guillermo Pickering (2010), en 1989 se inició en Chile una importante reestructuración de dicho sector, a partir de la dictación de un nuevo marco regulatorio, la Ley General de Servicios Sanitarios, el DFL No 382, que creó la Superintendencia de Servicios Sanitarios (SISS) y normó el funcionamiento de las empresas del sector. La incorporación de capital y gestión privada, en alianza con el Estado, permitió asegurar el financiamiento y operación de los sistemas que se requerían para el tratamiento de las aguas (Universidad de Chile, 2013). De acuerdo con Pickering, el avance de la población beneficiada fue notable, ya que para fines de 2010 se esperaba que el 90\% (13,5 millones de personas) tuviese cobertura en tratamiento de aguas servidas, mientras que para el 2012 se esperaba alcanzar el $100 \%$.

El crecimiento inmoderado de las ciudades o, más bien, una ampliación desordenada de una ciudad, sin la infraestructura sanitaria suficiente, tiene altas probabilidades de conducir a una mala calidad de vida. No contemplar aquello de forma previa a la planificación es, sin duda, una irresponsabilidad de quienes diseñan la ciudad, ya que la omisión de ese deber es el camino directo a la generación de problemas no solo sanitarios, sino que también de salud pública en general ${ }^{12}$. Se extrańa en este punto una política pública en materia sanitaria de forma específica ${ }^{13}$ en dicha área, ya que los tratamientos que se le han otorgado, hasta el minuto, operan en el contexto de la Estrategia Nacional de Salud para el cumplimiento de los Objetivos Sanitarios de la Década 2011-2020 y de la Política Nacional de Residuos 2018-2030, que responde a los compromisos internacionales adoptados por Chile con la OCDE, pendientes desde 2012.

En cuanto a materia energética, el abordaje de las energías desde una óptica multidisciplinar integrada al ambiente constituye un punto clave en los procesos de zonificación y planificación territorial, "ya que permite, entre otras cosas: Valorar los recursos energéticos renovables potenciales; Visualizar la demanda energética en toda su complejidad; Incorporar las perspectivas y visiones de los actores locales; Potenciar recursos y capacidades locales; Analizar impactos ambientales; Identificar las prioridades y orientar la planificación a corto y largo plazo de propuestas y acciones en cuestiones energéticas" (Belmonte et al, 2009, p. 07.41). Las cuestiones energéticas, como plantean los autores, se integran al territorio como demanda y problemática a resolver (requerimientos sociales y productivos), pero también como oportunidad y potencialidad para el cambio (mayor eficiencia, tecnologías nuevas, cuidado ambiental).

En el caso de la energía, Chile cuenta con instrumentos importantes en la materia, tales como la Estrategia Nacional de Energía 2012-2030, la Agenda de Energía. Un desafío país, progreso para todos y la Política Energética Nacional 2050. La primera, de febrero de 2012, recoge el desafío energético de Chile. En el documento se presentan las características fundamentales de los pilares energéticos del país y se incorporan algunas medidas legales, reglamentarias y administrativas e iniciativas público-privadas, necesarias para su implementación.

11 Hasta mediados del siglo pasado, Chile era uno de los países más rezagados de la región, con $60 \%$ de su población pobre y cerca del $25 \%$, analfabeta. Los indicadores de sanitarios tampoco eran buenos en 1950: la cobertura de agua potable era de $52 \%$ y la disponibilidad de alcantarillados, de 21\%. Según los datos estadísticos manejados por Forascepi, en 2014 la cobertura urbana en agua potable era del 99,9\% y el alcantarillado urbano cubría el $96,7 \%$ del país (Forascepi, 2018).

12 En este punto quisiera plasmar un ejemplo: las consideraciones técnicas que expresaron Óscar Figueroa y Luis Fuentes (2009) en torno al crecimiento desmesurado que tuvo el sistema urbano Iquique-Alto Hospicio, entre los ańos 1993 y 2003. Los autores percibieron que el problema para el crecimiento de la ciudad era la infraestructura sanitaria que, aunque hasta ahora es suficiente, manifiesta algunas externalidades. Para las zonas de expansión de Alto Hospicio hay factibilidad de servicio, lo cual disminuye los costos de urbanización en forma importante. En cambio, en las zonas de expansión de Iquique se cuenta con factibilidad hasta Los Verdes, pero el mayor problema se produce con el alcantarillado, debido a la lejanía de estas zonas respecto a los emisarios submarinos localizados en Barrio Industrial y Playa Brava.

13 Véase Ministerio de Salud (2018). "Nuevo modelo institucional y de gestión para el desarrollo de la infraestructura sanitaria del país". Disponible en: https://www.minsal.cl. 
Dicha estrategia observa que, en la medida que nuestro país crece, mayor energía requiere y se aumenta la necesidad de la renovación en infraestructura, produciéndose un natural acoplamiento entre economía y energía. En consecuencia, el desafío de Chile hoy es contar con recursos energéticos suficientes y competitivos para apoyar ese desarrollo. En efecto, la energía es un insumo esencial para la sociedad: su disponibilidad y abastecimiento influyen directamente en el crecimiento social y económico y, en consecuencia, en la reducción de la pobreza. La falta de acceso a fuentes y redes de energía confiables constituye, ciertamente, una peligrosa limitación para el progreso social sostenible, para el crecimiento económico y para el bienestar de la población (Ministerio de Energía, 2012, p. 6).

En la misma línea, la dependencia temporal de nuestra matriz a determinadas fuentes de suministro, en particular al gas argentino, también llevó a que la planificación y el desarrollo de la infraestructura de transmisión de energía eléctrica no considerasen lineamientos de largo plazo y la expansión de otras fuentes de generación, cuestión que la estrategia propone corregir en los años venideros.

En mayo de 2014 se dio a conocer la llamada Agenda de Energía. Un desafío país, progreso para todos, la cual expresa que "los actuales instrumentos de ordenamiento territorial se encuentran fragmentados en múltiples documentos - desde leyes hasta planos, pasando por estrategias, zonas protegidas, entre otros-, operando a diversas escalas territoriales y administrativas. Esta multiplicidad de instrumentos lleva en algunos casos a contradicciones y conflictos de competencia por el territorio, que dificultan su aplicación, generan incertidumbre en los distintos actores y complejizan las decisiones e inversiones que se quieran llevar adelante. Según esta propuesta, Chile necesita una normativa de Ordenamiento Territorial consistente, clara y legitimada por la ciudadanía. Sólo así haremos un uso del territorio que permita el desarrollo de Chile, donde las actividades productivas puedan dinamizar las regiones y las personas puedan vivir y surgir" (Ministerio de Energía, 2014, p. 85).

En el caso de la Política Nacional de Energía 2050 y su relación con la planificación territorial, impone desafíos a mediano y largo plazo. Se debe contar con que todas las regiones cuenten con planes energéticos regionales (los cuales se actualizan periódicamente, e incidan en los Planes Regionales de Ordenamiento Territorial (PROT)) y que las estrategias regionales de desarrollo y otros IPTs regionales y comunales contemplen adecuadamente los lineamientos de la política energética. Así, a largo plazo, al 2050 todos los asuntos relativos a energía debiesen estar contemplados dentro del ordenamiento territorial y ser abordados, principalmente, a través de la localización de infraestructura. Por lo tanto, el fin último es que todos los IPTs, sea a nivel regional y/o comunal, sean coherentes con los lineamientos de la política energética (Ministerio de Energía, 2015).

$\mathrm{Al}$ concluir lo relativo a la relación entre infraestructura y planificación territorial, paso a explicar la arista de los riesgos y protección del patrimonio natural y cultural.

\subsubsection{Riesgos y protección del patrimonio natural y cultural, y políticas públicas al respecto}

Los grandes lineamientos sobre la protección del patrimonio cultural de la nación derivan de la Constitución Política de la República de Chile que, en su artículo $19 \mathrm{~N}^{\circ} 10$, establece que "corresponde al Estado estimular la protección e incremento del Patrimonio Cultural de la Nación”.

En opinión de Ropert (2002), esta norma es de gran importancia, pues no solo entrega a los diversos órganos del Estado la tarea de proteger este tipo de bienes, sino que además expresa el deber fundamental de aumentarlos (p. 119). 
Es primordial sumar a la Carta Política, la actual PNDU, añadiendo a ella la Política Nacional de Cultura 2017-2022 y la Política de Fomento de la Arquitectura 2017-2022, ambas del Consejo Nacional de la Cultura y las Artes. Las tres debiesen ser ejes integrados entre sí para obtener una completa planificación territorial. No obstante, el legislador consciente de los riesgos al que se expone el patrimonio, contempla una serie de normas que operan como un marco de protección del patrimonio y la cultura.

En el caso particular de la LGUC, su Artículo 60 inciso $2^{\circ}$ expresa que el plan regulador señalará los inmuebles o zonas de conservación histórica, en cuyo caso los edificios existentes no podrán ser demolidos o refaccionados sin previa autorización de la Secretaría Regional de Vivienda y Urbanismo correspondiente. Además, resulta pertinente recordar que, de conformidad a la Ley $\mathrm{N}^{\circ} 17.288$ sobre Monumentos Nacionales, recaen en el Consejo de Monumentos Nacionales una serie de atribuciones, deberes y facultades para custodiar el patrimonio entendido de modo amplio.

En opinión de Mario Ferrada y Antonio Sahady (2013), si bien esta es una norma significativa, se advierten algunas falencias para la estabilidad y proyección temporal de las zonas e inmuebles de conservación histórica. Lo anterior, pues al incorporarse estas a los respectivos planes reguladores, quedan regidas por una ordenanza de nivel comunal que, si bien tiende a lograr una buena integración en el contexto de la planificación territorial, adolece de tal inestabilidad, que las deja expuestas al arbitrio de las presiones del mercado y la voluntad de las autoridades de turno, siempre facultadas para cambiar las normas. Les basta modificar el plan regulador o los planos seccionales, con el consiguiente riesgo de destrucción de valiosos edificios y conjuntos urbanos que constituyen un patrimonio no renovable (p. 275).

Realizados los alcances normativos y de políticas públicas pertinentes para este literal, procederé a desarrollar la relación existente entre la planificación territorial y la dimensión patrimonial y cultural que le acompaña.

El patrimonio, en su sentido más amplio, es considerado hoy día como "un conjunto de bienes materiales e inmateriales, heredados de nuestros antepasados, que han de ser transmitidos a nuestros descendientes acrecentados. Consideramos patrimonio cultural el conjunto de objetos materiales e inmateriales, pasados y presentes, que definen a un pueblo: lenguaje, literatura, música, tradiciones, artesanía, bellas artes, danza, gastronomía, indumentaria, manifestaciones religiosas y, por supuesto, la historia y sus restos materiales, es decir, el patrimonio histórico. Entendemos por patrimonio natural todos los elementos de la naturaleza: montañas, ríos, flora, fauna, así como el resultado del trabajo del hombre en el ambiente natural, es decir, el paisaje humanizado: caminos, ciudades y pueblos, cultivos, caseríos agrícolas, etc." (García, 2012, pp. 17-18).

Ahora bien, el concepto de patrimonio no ha sido estable a lo largo de la historia de la humanidad; su noción depende en gran parte del contexto en el que se formule y también de quién y cómo lo formule (Conferencia Mundial sobre las Políticas Culturales, 1982, p. 3). Esta noción poco estable a la que me refiero no solo abarca la dificultad de coincidir en un concepto de patrimonio, sino que también puede alcanzar a las reacciones de grupos gremiales frente a decisiones de la Administración en materia patrimonial. Por ejemplo, la desafectación de bienes considerados monumentos nacionales bajo un contexto histórico, para luego retractarse de esa decisión por "predominio de valoraciones y voluntades de índole político por sobre las técnicas que debiesen primar” (Lawner, 2019, p. 32).

Por lo anterior, García (2012) sostiene que el patrimonio no es un concepto quieto y que pueda ser asumido de manera universal, como si por él no pasase el tiempo. La pregunta que debe plantearse aquí es cuál es la relación entre patrimonio y la planificación territorial. Esta autora lo describe, señalando 
que el territorio "es el punto de encuentro del hombre con su patrimonio. Sin una valoración cultural del territorio que ponga de manifiesto la singularidad de sus recursos y estimule la confianza de la comunidad en sí misma y en su capacidad creativa, es difícil que un lugar despegue en su desarrollo económico" (p. 18).

Ahora bien, entre las dimensiones que reconoce la actual PNDU, se encuentran: la integración social, el desarrollo económico y el equilibrio ambiental. Sin embargo, se estimó que igual peso le correspondía tener a la protección y puesta en valor del patrimonio como eje fundacional de la identidad de nuestras comunidades. En otras palabras, se estimó que el país debía lograr el desarrollo, pero dando cuenta del sentido de pertenencia de las personas y comunidades, reflejando sus valores, su historia y cultura.

El objetivo central del ámbito de identidad y patrimonio de la PNDU establece que "las ciudades y centros poblados deben dar cuenta de la identidad de los lugares en que se emplazan, de las personas que los habitan y de la diversidad geográfica y la riqueza cultural propia de las diferentes comunidades, pueblos y localidades. Identidad significa también 'identificación', en el sentido de que las comunidades deben sentirse reflejadas en las características de los lugares donde viven" (Ministerio de Vivienda y Urbanismo y Programa de las Naciones Unidas para el Desarrollo, 2014, p. 49). En esa línea, se define el patrimonio como "un bien social que está conformado tanto por las obras y manifestaciones de las personas como por el entorno natural en que viven" (íbid), haciendo referencia al patrimonio cultural, entendido como "aquel que tiene un significado o valor especial para el país o una comunidad en particular" (íbid).

La PNDU precisa para este ámbito tres objetivos específicos, los cuales, a su vez, poseen diversos lineamientos para poder cumplirlos. Los objetivos son: valorar el entorno físico, construido o natural, formador de la identidad de las comunidades; valorar la identidad de cada cultura y zona geográfica, y conocer, valorar, proteger y gestionar el patrimonio cultural.

Con lo relatado hasta este punto, podría pensarse que la relación que efectúa la PNDU entre el patrimonio y el territorio, como ámbito temático, constituye un piso suficiente para avanzar en temas territoriales. Sin embargo, aquello no es así, ya que la Administración quiso dar otras señales de avance, ahora en materia de la vinculación existente entre territorio, cultura y arquitectura. En ese contexto surgen otras dos política públicas: la Política Nacional de Cultura 2017-2022 y la Política de Fomento de la Arquitectura 20172022, ambas del Consejo Nacional de la Cultura y las Artes, como se mencionó.

En el marco conceptual de la primera, para el enfoque territorial en el diseño de políticas culturales, se señala que "el territorio es uno de los espacios de representación cultural de los grupos humanos. En él tienen cabida las relaciones sociales marcadas por su historia, religión, expresiones culturales y formas de hacer, estar y de concebir el mundo, diferenciándose de un 'otro' que a su vez tiene sus propias prácticas culturales. En este sentido, como señala Giménez (1999), los territorios están 'tatuados' por su cultura y su historia, forjando la 'identidad territorial' de las comunidades que lo habitan. Desde el ámbito de la construcción de políticas públicas, resulta importante considerar al territorio como un conjunto de realidades y agentes con los que el Estado debe relacionarse, incorporando sus especificidades para generar políticas pertinentes" (Consejo Nacional de la Cultura y las Artes, 2017, p. 32). En la misma línea, la segunda política pública mencionada relaciona la planificación territorial con la arquitectura, pues esta disciplina "se presenta como una oportunidad para mejorar la calidad del entorno construido y contribuir al fortalecimiento de las relaciones sociales de una manera más justa y equitativa, abordando problemáticas como la sostenibilidad, la inequidad, la segregación y la carencia de cohesión social” (p. 24). 


\section{Conclusiones}

1. La legislación urbanística, en general, es normalmente desigualitaria en deberes y cargas, siendo, además, extremadamente técnica, como lo reflejan la LGUC y su Ordenanza. Sin embargo, producto de la reforma legal y las políticas públicas reseñadas en este artículo, se han incorporado directrices y consensos fundamentales para migrar hacia una planificación territorial basada en principios jurídicos específicos del Derecho Urbanístico en particular.

2. Tanto la PNDU como la PNOT son instrumentos de trabajo relativamente recientes, al igual que la Ley $\mathrm{N}^{\circ} 21.078$ y la Ley $\mathrm{N}^{\circ} 21.074$. La primera política pública solo lleva cinco años en ejecución y la segunda, si bien está afinada, requiere aún que la Contraloría General de la República proceda a la toma de razón de ella. En el caso de las últimas leyes mencionadas, se encuentran vigentes solo desde agosto de 2018. Lo anterior implica esperar las reacciones progresivas de los órganos de la Administración del Estado involucrados en planificación territorial para que plasmen en sus IPTs todos y cada uno de los estándares analizados a nivel legal.

3. La PNDU y la PNOT son herramientas de trabajo complementarias entre sí, pues son consensos políticos alcanzados con la participación de la ciudadanía, que aportan directrices fundamentales para el urbanismo. Sin embargo, para efectos de obligatoriedad positiva, ha de mencionarse que cada uno de los estándares analizados en el Artículo 28 decies de la LGUC son el reflejo a nivel normativo y práctico de los distintos ámbitos temáticos de la PNDU. A saber, la integración social, el desarrollo económico, el equilibrio ambiental, la identidad y patrimonio, y la institucionalidad y gobernanza.

4. La exigencia del primer estándar relativo a la motivación hace posible que opere el principio de impugnabilidad de los actos administrativos, por la vía de los recursos. Esto, sea a través de los recursos administrativos y/o jurisdiccionales, ya que al exteriorizar las razones o motivos que se consideraron como fundamentos de la decisión, se garantiza que, en forma coetánea, operen los diversos mecanismos de control a la que está sometida toda función administrativa.

5. La exigencias del segundo estándar, esto es, considerar información suficiente sobre la realidad existente y su evolución previsible, responde más bien a los aspectos metodológicos de características cuantitativas, que ayudan a orientar el desarrollo de la planificación territorial, desde el planteamiento del problema terrestre hasta finiquitar su ejecución.

6. En las exigencias del tercer y quinto estándar confluyen en sí los distintos ámbitos temáticos de la PNDU, dando una mirada conjunta con los principios de sustentabilidad, diversidad territorial, equidad territorial, integralidad, dinamización productiva y competitividad territorial, participación, descentralización y gradualidad, que animan a la PNOT.

7. En cuanto al cuarto estándar, a saber, evitar la especulación y procurar la satisfacción de las necesidades de vivienda de la población, responde a la mirada ética de todo proceso planificador.

\section{Bibliografía citada}

Belmonte, Silvina et al (2009): "Integración de las Energías Renovables en procesos de Ordenamiento Territorial”, Revista Avances en Energías Renovables y Medio Ambiente, vol. 13: pp. 07.41-07.48.

Betsalel Palombo, María Eugenia (2001): "Los instrumentos de planificación territorial”, Revista Urbano, vol. 4, $\mathrm{N}^{\circ}$ 5: pp. 71-76. 
Biblioteca del Congreso Nacional de Chile (2017): Diario de Sesión. Sesión Ordinaria Nº 12 . Legislatura número 365. Mejoramiento en nivel de transparencia de mercado de suelo e incremento de valor por ampliaciones de límite urbano. Disponible en: https:/www.bcn.cl/laborparlamentaria/wsgi/ consulta/verParticipacion.py?idParticipacion=1487127 [Fecha de consulta: 7 de octubre de 2020].

Biblioteca del Congreso Nacional de Chile (2018). Historia de la Ley $\mathrm{N}^{\circ}$ 21.078. Sobre transparencia del mercado del suelo e impuesto al aumento de valor por ampliación del límite urbano. Disponible en: https://www.bcn.cl/historiadelaley/fileadmin/file_ley/7496/ HLD_7496_5fc736c5417e125533e0bf8b6fab02db.pdf [Fecha de consulta: 7 de octubre de 2020].

Capdeferro Villagrasa, Óscar (2015): “La corrupción en el Urbanismo: análisis del fenómeno y propuestas para su prevención”, Revista de Derecho Urbanistico y Medioambiente, № 297: pp. 233-248.

Carrasco Carrasco, Mauricio (2008): "Plan Regulador comunal como herramienta de gestión para una ciudad intermedia. Los Ángeles”, Revista Urbano, vol. 11, N 17: pp. 83-88.

Castro Castro, Luis Javier (2018): "La Planeación Sostenible de Ciudades. Propuestas para el desarrollo de infraestructura" en Luis Javier Castro Castro (coordinador), La Planeación Sostenible de Ciudades: Propuestas para el desarrollo de infraestructura (México, Ediciones Científicas Universitarias), pp. 9-14.

CEPAL (2016): "Planificación y prospectiva para la construcción de futuro en América Latina y el Caribe". Disponible en: https://repositorio.cepal.org/bitstream/handle/11362/40623/4/S1600345_ es.pdf. [Fecha de consulta: 24 de diciembre de 2019].

Consejo Nacional de la Cultura y las Artes (2017): Política Nacional de Cultura 2017-2022. Cultura y Desarrollo Humano: Derechos y Territorio. Disponible en: https://www.cultura.gob.cl/politicasculturales/wp-content/uploads/sites/2/2018/01/politica-nacional-cultura-2017-2022.pdf [Fecha de consulta: 9 de octubre de 2020].

Cordero Cueva, Fernando (2016): “El gran desordenador urbano: la especulación”, en Fernando Cordero Cueva (coordinador), Autonomias y Ordenación Territorial y Urbanístico: Memorias del IX Simposio Nacional de Desarrollo Urbano y Planificación Territorial (Ecuador, Universidad de Cuenca), pp.176191.

Costa, Aline y Hernández, Agustín (2010): "Análisis de la de la situación actual de la regularización urbana en América Latina: La cuestión de la tenencia segura de los asentamientos informales en tres realidades distintas: Brasil, Colombia y Perú”, Revista INVI, vol. 25, Nº 68: pp. 121-152.

Cordero Quinzacara, Eduardo (2007): “El Derecho Urbanístico, los Instrumentos de Planificación Territorial y el régimen jurídico de los bienes públicos”, Revista de Derecho de la Pontificia Universidad Católica de Valparaíso, N²9: pp. 269-298.

Cordero Quinzacara, Eduardo (2011): "Ordenamiento Territorial, Justicia Ambiental y Zonas Costeras", Revista de Derecho de la Pontificia Universidad Católica de Valparaíso, XXXVI: pp. 209-249.

Crisosto, Rafael (2017): “Una red de incertidumbre en la planificación de megaproyectos urbanos: el caso de la ciudad satélite de Alerce, Chile”, EURE, vol. 43, N 128: pp. 229-249.

Cuenya, Beatriz y Corral, Manuela (2011): "Empresarialismo, economía del suelo y grandes proyectos urbanos: el modelo de Puerto Madero en Buenos Aires”, EURE, vol. 37, N 111: pp. 25-45.

Eliash Díaz, Humberto (2005): "La forma sigue a la gestión: nuevos referentes en la práctica arquitectónica actual”, Revista de Arquitectura, vol.11, No 12: pp. 44-47.

Escudero, Natalia (2013): "Movilidad Sustentable, eje estructurante de la Nueva Política Nacional de Desarrollo Urbano”, en Ernesto López, Camilo Arriagada, Paola Jirón, Humberto Eliash (editores), 
Chile Urbano hacia el siglo XXI: investigaciones y reflexiones de Politica Urbana desde la Universidad de Chile (Santiago de Chile, Editorial Universitaria), pp. 212-218.

Farinós Dasí, Joaquín (2007): "Planificación de Infraestructuras y Planificación Territorial. Gobernanza y gestión de dinámicas multiescalares”, Papers Regió Metropolitana de Barcelona: Territori, estrategias, planajemet, $\mathrm{N}^{\circ}$ 44: pp. 33-42.

Fernández Fernández, Antonio y Muguruza Cañas, Carmen (2015): Ordenación del territorio: Análisis y Diagnóstico, (Madrid, UNED).

Fernández Güell, José Miguel (2008): “Estrategia de Ciudades”. Disponible en: http://oa.upm.es/4755/1/ INVE_MEM_2008_56113.pdf. [Fecha de consulta: 10 de octubre de 2019].

Fernández Güell, José Miguel (2015): “Ciudades Inteligentes: La mitificación de las nuevas tecnologías como respuesta a los retos de las ciudades contemporáneas", Revista Economía Industrial, № 395: pp. 17-28.

Fernández Tabales, Alonso et al (2009): "El concepto de cohesión territorial. Escalas de aplicación, sistemas de medición y políticas derivadas”, $B A G E$, $\mathrm{N}^{\circ}$ 50: pp. 57-172.

Ferrada, Mario y Sahady, Antonio (2013): "El rol del patrimonio cultural en el desarrollo urbano de Chile en el siglo XXI”, en Ernesto López, Camilo Arriagada, Paola Jirón, Humberto Eliash (editores), Chile Urbano hacia el siglo XXI: investigaciones y reflexiones de Politica Urbana desde la Universidad de Chile (Santiago de Chile, Editorial Universitaria), pp. 273-278.

Figueroa, Óscar y Fuentes, Luis (2009): "Expansión Urbana y Desarrollo Económico: El Caso del Sistema Urbano Iquique-Alto Hospicio", en Rodrigo Hidalgo, Carlos A. de Mattos y Federico Arenas (editores.), Chile: Del país urbano al país Metropolitano (Santiago de Chile, Pontificia Universidad Católica de Chile), pp. 149-159.

Forascepi Crespo, Constanza (2018): "Chile: nuevos desafíos sanitarios e institucionales en un país en transición”. Disponible en https://www.ncbi.nlm.nih.gov/pmc/articles/PMC6385805/ [Fecha de consulta: 26 de diciembre de 2019]

García Cuetos, María Pilar (2012): El Patrimonio Cultural. Conceptos básicos (España, Prensas de la Universidad de Zaragoza).

Gómez Orea, Domingo (2008): Ordenación Territorial (Madrid, Mundi-Prensa, segunda edición ampliada).

González, Rubén (2006): "Planes Maestros como herramienta de gestión de Megaproyectos de Diseño Urbano liderados por el Estado y ejecutados por el sector privado: El caso del Portal Bicentenario Cerrillos", Revista de Arquitectura, vol.12, N¹3: pp. 67-76.

Guasch, José Luis (2005): Concesiones en infraestructura: cómo hacerlo bien (Barcelona, Antoni Bosch Editor).

Lawner, Miguel (2019): “La Villa San Luis, o Quiénes escriben la historia. Fulgor y Agonía de la Villa San Luis", Crítica Urbana, N ${ }^{\circ}$ : pp. 29-34.

León Aravena, Javier et al (2019): "Participación ciudadana y movilidad sostenible: El caso del área Metropolitana de Concepción Chile", Revista de Urbanismo, № 40: pp. 1-18.

López, María José y Faginas, Verónica Lucía (2019): "El espacio público como elemento de cohesión territorial”, Revista Turismo y Sociedad, XXV: pp. 131-149.

Lozano, Angélica (2018): "Hacia un transporte urbano realmente sostenible", en Luis Javier Castro Castro (coordinador), La planeación sostenible de ciudades: propuestas para el desarrollo de infraestructura (Ciudad de México, Fondo de Cultura Económica), pp. 65-78. 
Maqueda, Santiago (2010): "El sentido de los elementos del acto administrativo", Revista Díkaion, vol. 19, $\mathrm{N}^{\circ} 2$ : pp. 467-487.

Martínez López, Miguel (2005): "Sociologías del espacio: Legado Teórico y productividad empírica", Revista Española de Investigaciones Sociológicas, № 109: pp.127-154.

Martínez López, Miguel (2007): “La Especulación Urbana: persistencias estructurales y resistencias sociales", Intersticios Revista Sociológica de Pensamiento Critico, vol.1: pp. 37- 47.

Ministerio de Energía (2012): “Estrategia Nacional de Energía 2012-2030”. Disponible en: https://mma. gob.cl/wp-content/uploads/2014/10/3_Estrategia-Nacional-de-Energia-2012-2030_Energiapara-el-Futuro.pdf. [Fecha de consulta: 10 de diciembre de 2019].

Ministerio de Energía (2014): "Agenda de Energía un desafío país, progreso para todos". Disponible en: https://www.chileenergias.cl/wp-content/uploads/2015/09/AgendaEnergiaMAYO2014_ FINAL-2.pdf. [Fecha de consulta: 25 de diciembre de 2019].

Ministerio de Energía (2015): "Política Energética de Chile 2050". Disponible en: http://www.energia2050. cl/wp-content/uploads/2016/07/Politica-Energetica-Nacional.pdf. [Fecha de consulta: 10 de diciembre de 2019].

Ministerio del Interior y Seguridad Pública (2019) Política Nacional de Ordenamiento Territorial. Disponible en https://www.contraloria.cl/documents/451102/3103767/Dto+469-2019+Sub+ Interior+3er.+ingreso.pdf/700e786e-fac2-5bc6-bfbe-911dad812603. Tercer reingreso a Contraloría General de la República. [Fecha de consulta 23 de octubre de 2020]

Ministerio de Vivienda y Urbanismo y Programa de las Naciones Unidas para el Desarrollo (2012): Hacia una nueva Politica Urbana para Chile. Antecedentes Históricos (Santiago de Chile, LOM), Vol. 1.

Ministerio de Vivienda y Urbanismo y Programa de las Naciones Unidas para el Desarrollo (2014): "Hacia una Nueva Política Urbana para Chile. Política Nacional de Desarrollo Urbano. Ciudades Sustentables y Calidad de Vida”. Disponible en: https://cndu.gob.cl/wp-content/uploads/2014/10/ L4- Politica-Nacional-Urbana.pdf. [Fecha de consulta: 19 de enero de 2020].

Noguera, Juli Esteban (2011): La Ordenación Urbanistica: Conceptos, Herramientas y Prácticas (Barcelona, Iniciativa Digital Politécnica).

Pérez Ramírez, Rigoberto (2016): "Corrupción y costos de transacción en la administración pública", Revista Iberoamericana de las Ciencias Sociales y Humanisticas, vol. 5, № 10: pp. 188-213.

Pickering, Guillermo (2010): "Infraestructura sanitaria en Chile: desarrollo con el medioambiente". Disponible en: https://www.americaeconomia.com/analisis-opinion/infraestructura-sanitaria-enchile-desarrollo-amable-con-el-medioambiente. [Fecha de consulta: 4 de diciembre de 2019].

Radio Concierto (2013): Entrevista a Genaro Cuadros Ibánez. Disponible en https://www.concierto. cl/2013/05/genaro-cuadros-arquitecto-urbanista-de-la-udp-el-nuevo-plan-regulador-desantiago-es-agregar-metros- cuadrados-a-una-ciudad-que-tiene-muchas-dificultades-parafuncionar/. [Fecha de consulta: 26 de noviembre de 2019].

Rajevic Mosler, Enrique (2013): "Derecho Urbanístico y segregación socio-espacial: Mecanismos que favorecen la segregación e instrumentos que favorecen la integración residencial”, en Pía Mora (editora), Seminario Internacional Grandes líneas de politica urbana para la promoción de la integración social (Santiago de Chile), pp. 42-48.

Real Academia Española: "Diccionario de la Lengua Española” (23a ed.). Disponible en: https://dle.rae. es/ [Fecha de la consulta: 13 de febrero de 2020].

Ropert Fuentes, Rodrigo (2002): "La conservación del patrimonio cultural urbano en el ordenamiento jurídico chileno", Revista de Derecho Ambiental, N 1: pp. 118-140. 
Salas Bourgoin, María Andreina (2013): Prospectiva territorial. Aproximación a una base conceptual y metodológica (Mérida, CDCHTA-ULA).

Salas, Erik y Budde, Friedhelm (2008): Planificación y Proyectos Territoriales. Estudio sobre métodos y buenas prácticas de la planificación de proyectos territoriales con un enfoque integral. Disponible en: http://www.desarrollosocialyfamilia.gob.cl/btca/txtcompleto/mideplan/planifyproy.territ-enf. integral.pdf. [Fecha de consulta: 3 de enero de 2020].

Santa Cruz Chao, José (2014): Más ciudad: análisis, diagnóstico y plan (Madrid, Dykinson).

Torres Jofré, Mario (2005): "Planeación urbana en Chile. Un producto de la especulación inmobiliaria", Boletin $C F+S$, No 29/30: pp. 53-81.

Tórtora Aravena, Hugo (2012): "El derecho a la vivienda adecuada o digna”, en Gonzalo Aguilar Cavallo (coordinador), Derechos económicos, sociales y culturales en el orden constitucional chileno (Santiago de Chile, Librotecnia), pp. 347-367.

Trivelli Oyarzun, Pablo (2011): "La propuesta de modificación del Plan Regulador Metropolitano de Santiago PRMS 100 requiere una justificación más sólida”, EURE, vol. 37, № 111: pp. 179-184.

Unesco. Conferencia Mundial sobre las Políticas Culturales (1982): "Declaración de México sobre las políticas culturales”. Disponible en: https://culturalrights.net/descargas/drets_culturals400.pdf [Fecha de consulta: 28 de noviembre de 2019].

Universidad de Chile. Centro de Análisis de Políticas Públicas del inap (2013): "Informe País Estado del Medio Ambiente en Chile 2012”. Disponible en: https://www.uchile.cl/publicaciones/97817/ informe-pais-estado-del-medio-ambiente-en-chile-2012. [Fecha de consulta: 20 de noviembre de 2019].

Vergara Blanco, Alejandro (2012): "Los principios jurídicos y la tarea de construir el Derecho Administrativo en clave científica", Revista de Derecho Administrativo, N 6: pp. 63-80.

\section{Normas citadas}

Constitución Política de la República de Chile (1980).

Decreto N 458 (13/04/1976) Ley General de Urbanismo y Construcciones.

Ley $\mathrm{N}^{\circ} 18.575$ (05/12/1986) Ley Orgánica Constitucional de Bases de la Administración del Estado.

Ley N 19.880 (29/05/2003) Sobre Bases de los Procedimientos Administrativos que rigen los actos de los órganos de la Administración del Estado.

Decreto N 78 (04/03/2014) Fija Política Nacional de Desarrollo Urbano y Crea Consejo Nacional de Desarrollo Urbano

Real Decreto Legislativo 7/2015, de 30 de octubre (31/10/2015) Por el que se aprueba el texto refundido de la Ley de Suelo y Rehabilitación Urbana.

Ley N ${ }^{\circ} 21.078$ (15/02/2018) Sobre Transparencia del Mercado del suelo e Impuesto al aumento de valor por ampliación del límite urbano. 